\title{
PENGARUH KONSENTRASI IBA (INDOLE BUTYRIC ACID) DAN JENIS MEDIA TANAM TERHADAP PERTUMBUHAN BIBIT NANAS (Ananas comosus [L.] Merr) ASAL TUNAS MAHKOTA
}

\author{
Fidia Octavia Sari, Rugayah \& Yohannes C. Ginting \\ Jurusan Agroteknologi, Fakultas Pertanian Universitas Lampung \\ Jl. Prof. Dr. Sumantri Brojonegoro I, Bandar Lampung 35145 \\ E-mail:dafhi27@yahoo.co.id
}

\begin{abstract}
The research was conducted to determine the effects of IBA concentration on the growth of pineapple seedlings sprout from crown cutting on each type of growing media. The treatment was arranged in factorial $(5 \times 2)$ in randomized block design with three replications. The first factor is the concentration of IBA (A), which consists of: without IBA ( $\left.\mathrm{A}_{0}\right)$, IBA $100 \mathrm{ppm}\left(\mathrm{A}_{1}\right)$, IBA $200 \mathrm{ppm}\left(\mathrm{A}_{2}\right)$, IBA $400 \mathrm{ppm}\left(\mathrm{A}_{3}\right)$, and IBA $600 \mathrm{ppm}\left(\mathrm{A}_{4}\right)$. The second factor is the type of planting medium $(\mathrm{B})$, which consists of river sand $\left(B_{1}\right)$ and volcanic sand $\left(B_{2}\right)$. The results showed that the concentration of IBA 600 ppm treatment effect on seedling growth shown by the increasing number of roots produced. Treatment planting medium used had no effect on all observed variables. IBA concentration on root wet weight depending on the type of planting medium used.
\end{abstract}

Key words: concentration of IBA (Indole Butyric Acid), pineapple, types of media planting.

\section{PENDAHULUAN}

Nanas merupakan salah satu jenis buah-buahan yang memiliki nilai jual baik pasar dalam negeri maupun pasar luar negeri. Permintaan pasar dalam negeri terhadap buah nanas cenderung meningkat sejalan dengan peningkatan kesadaran masyarakat terhadap kebutuhan gizi dan meningkatnya permintaan bahan baku industri pengolahan buah-buahan. Peningkatan permintaan harus diimbangi dengan peningkatan produksi.

Berdasarkan data Badan Pusat Statistik (2011) produksi buah nanas di Indonesia selama 5 tahun terakhir, terhitung sejak tahun 2005 hingga 2010 mengalami peningkatan yang cukup signifikan yaitu sebesar $\pm 45 \%$. Tahun 2005 produksi nanas sebanyak 925.082 ton per tahun dan tahun 2010 produksi nanas mencapai angka 1.406.445 ton per tahun.

Peningkatan produksi ini harus diimbangi dengan penyediaan bahan tanam nanas yang banyak dan berkualitas. Menurut Samson (1986), tanaman nanas dapat diperbanyak secara vegetatif dengan menggunakan cabang-cabang vegetatif seperti tunas yang tumbuh dari bawah permukaan tanah (ratoon sucker), tunas yang tumbuh dari mata tunas aksilar pada batang (shoot), tunas yang tumbuh di dasar buah (slips), dan tunas yang tumbuh di pucuk buah (crown). Semua materi perbanyakan tersebut memiliki keterbatasan dalam jumlah yang dihasilkan.

Jumlah materi tanam yang terbatas menjadi kendala dalam penyediaan bibit dalam jumlah banyak dan seragam. Salah satu upaya yang dapat dilakukan adalah dengan penyetekan tunas mahkota, namun tunas yang tumbuh tidak disertai dengan pertumbuhan perakaran yang padat. Oleh karena itu, perlu dilakukan upaya untuk meningkatkan pertumbuhan akar pada bibit hasil penyetekan tunas mahkota dengan menggunakan zat pengatur tumbuh (ZPT) golongan auksin, seperti IBA (Indole Butyric Acid). Pemberian ZPT itu sendiri dapat dilakukan dengan beberapa cara, antara lain dengan perendaman, pasta, atau penyemprotan.

Hasil yang dilaporkan oleh Ardisela (2010) bahwa penggunaan bibit crown yang diberi Rootone-F 100 200 ppm lebih cepat tumbuh dibandingkan tanpa rootoneF. Rosmaina (2011) menunjukkan bahwa induksi akar nenas secara in vitro pada media perakaran yang berBA 17,76 uM dan NAA 2,00 uM tidak meningkatkan jumlah akar, tetapi menghasilkan panjang akar yang terpanjang $(4,2 \mathrm{~cm})$.

Keberhasilan perkembangan perakaran selain dengan penggunaan ZPT juga ditentukan oleh pemilihan media tanam yang tepat. Media tanam yang baik adalah (1) cukup kuat untuk menahan pertumbuhan, (2) mampu menahan kelembaban, (3) sistem aerasi dan drainase 
yang baik, (4) bebas dari bibit penyakit dan (5) salinitas rendah (Hartmann et al., 1997).

Keberhasilan setek tunas mahkota harus ditunjang oleh media tanam yang baik dan sesuai dengan karakter tanaman. Oleh karena itu diperlukan adanya komposisi media tanam yang tepat. Beberapa jenis bahan organik yang biasa digunakan sebagai media tanam antara lain arang sekam dan kompos yang dicampur dengan bahan anorganik seperti pasir kali atau pasir vulkanik.

Pasir dianggap sesuai dan memadai sebagai media pertumbuhan dan perakaran karena mempunyai bobot yang cukup berat sehingga mempermudah tegaknya setek. Pasir vulkanik adalah batuan beku berupa lava dengan komposisi basaltic atau andesitic dengan struktur scoria atau vesicular (mempunyai rongga-rongga) akibat keluarnya gelembung gas selama erupsi. Berdasarkan hasil penelitian Rachmawati (2008) pada setek sirih merah, bahwa pemberian IBA 1000 ppm dengan media pasir vulkanik, persentase tumbuh setek paling tinggi yaitu 93.3\%. Hal ini karena pasir vulkanik memiliki porositas yang tinggi dengan memiliki banyak kandungan mineral yang tergolong hara mikro dibandingkan pasir kali (Adesidjo, 2008).

Namun perlakuan serupa belum banyak dicoba pada setek tunas mahkota nanas dengan menggunakan konsentrasi IBA yang lebih rendah. Oleh karena itu, perlu dilakukan penelitian untuk mengetahui pengaruh konsentrasi IBA (Indole Butyric Acid) dan jenis media tanam terhadap pertumbuhan bibit nanas (Ananas comosus [L.] Merr) asal tunas mahkota.

Penelitian ini bertujuan untuk (1) mengetahui pengaruh konsentrasi IBA terhadap pertumbuhan bibit nanas asal tunas mahkota, (2) mengetahui pengaruh jenis media tanam terhadap pertumbuhan bibit nanas asal tunas mahkota, dan (3) mengetahui pengaruh konsentrasi IBA terhadap pertumbuhan bibit nanas asal tunas mahkota pada masing-masing jenis media tanam.

\section{BAHAN DAN METODE}

Penelitian ini dilaksanakan pada Februari sampai Mei 2012 di rumah kaca gedung Hortikultura, Fakultas Pertanian Universitas Lampung. Metode yang digunakan pada penelitian ini adalah rancangan kelompok teracak sempurna secara faktorial $(5 \times 2)$. Faktor pertama yaitu konsentrasi IBA (A), yang terdiri dari: tanpa IBA $\left(\mathrm{A}_{0}\right)$, IBA $100 \mathrm{ppm}\left(\mathrm{A}_{1}\right)$, IBA $200 \mathrm{ppm}\left(\mathrm{A}_{2}\right)$, IBA 400 ppm $\left(\mathrm{A}_{3}\right)$, dan IBA $600 \mathrm{ppm}\left(\mathrm{A}_{4}\right)$. Faktor kedua adalah jenis media tanam (B) yang terdiri dari campuran media pasir kali, sekam bakar, dan kompos $\left(\mathrm{B}_{1}\right)$ dan campuran pasir vulkanik sekam bakar, dan kompos; masing-masing dengan perbandingan volume $1: 1: 1\left(\mathrm{~B}_{2}\right)$. Setiap satuan percobaan yang terdiri dari empat bibit diulang sebanyak tiga kali, sehingga total bibit 120 batang.

Bahan tanam yang digunakan dalam penelitian ini adalah bibit nanas yang berasal dari mahkota buah (crown) kultivar Smooth cayenne yang telah berumur 9 bulan setelah persemaian. Bibit yang digunakan ratarata telah memiliki 10 helai daun dengan tinggi berkisar $14-25 \mathrm{~cm}$. Akar yang ada semuanya dipotong dengan menggunakan gunting. Setiap pot yang digunakan masing-masing ditanami 1 bibit nanas. Media tanam yang digunakan sesuai dengan perlakuan. Pemberian IBA dalam bentuk larutan dilakukan dengan cara penyemprotan sebelum bibit nanas ditanam ke dalam pot yang telah diisi media perlakuan. Penyemprotan IBA dilakukan secara berulang masing-masing sebanyak tiga kali yang diberikan pada pangkal tanaman sesuai dengan konsentrasi pada setiap perlakuan dan kemudian dikeringanginkan selama satu jam. Volume semprot yang digunakan sebanyak $2 \mathrm{ml}$ per bibit.

Pengamatan dilakukan pada akhir penelitian yaitu saat bibit berumur 12 bulan, atau berumur 3 bulan sejak bibit dipindahkan ke dalam pot perlakuan. Variabel yang diamati adalah penambahan jumlah akar, panjang akar primer, bobot basah akar, dan bobot kering akar primer, tinggi tanaman, penambahan jumlah daun, panjang daun, dan penambahan bobot basah tajuk tanaman. Data dianalisis dengan sidik ragam dan dilanjutkan dengan uji BNT 5\%.

\section{HASIL DAN PEMBAHASAN}

Hasil penelitian menunjukkan bahwa perlakuan konsentrasi IBA (Indole Butyric Acid) berpengaruh nyata pada jumlah akar primer bibit tanaman nanas (Tabel 1), tetapi tidak berpengaruh pada panjang akar primer, bobot basah akar, bobot kering akar, tinggi tanaman, jumlah daun, panjang daun, lebar daun, dan bobot basah tajuk tanaman (Tabel 2). Jenis media tanam tidak berpengaruh nyata pada seluruh variabel pengamatan. Interaksi antara konsentrasi IBA dan jenis media tanam hanya berpengaruh nyata pada bobot basah akar (Tabel 3).

Perlakuan konsentrasi Indole Butyric Acid (IBA) hanya berpengaruh pada jumlah akar nanas yang dihasilkan. Menurut Irwanto (2001) bahwa IBA memiliki sifat penyebaran yang sangat kecil, sehingga apabila IBA diberikan pada akar, ia hanya akan menstimulasi pada bagian akar saja, dan kemungkinan kecil untuk mampu menstimulasi pertumbuhan pada bagian atas tanaman.

Sejalan dengan hasil penelitian yang dilakukan oleh Kapisa dan Sapulete (1994), bahwa pemberian IBA tidak berpengaruh pada pertambahan daun dari setek 
Tabel 1. Pengaruh perlakuan konsentrasi IBA (Indole Butyric Acid) dan jenis media tanam terhadap jumlah akar primer bibit tanaman nanas

\begin{tabular}{lc}
\hline Perlakuan & Nilai tengah jumlah akar (buah) \\
\hline Tanpa IBA & $9,24 \mathrm{c}$ \\
Konsentrasi IBA $100 \mathrm{ppm}$ & $10,33 \mathrm{bc}$ \\
Konsentrasi IBA $200 \mathrm{ppm}$ & $12,10 \mathrm{ab}$ \\
Konsentrasi IBA $400 \mathrm{ppm}$ & $11,20 \mathrm{ab}$ \\
Konsentrasi IBA $600 \mathrm{ppm}$ & $12,30 \mathrm{a}$ \\
\hline BNT & 1,95 \\
\hline Media tanam pasir kali & $11,50 \mathrm{a}$ \\
Media tanam pasir vulkanik & $10,57 \mathrm{a}$ \\
\hline BNT & 1,23 \\
\hline
\end{tabular}

Keterangan: Angka-angka diikuti dengan huruf yang sama menunjukkan tidak berbeda nyata berdasar uji BNT pada $\alpha=0,05$.

Tabel 2. Pengaruh perlakuan konsentrasi IBA dan jenis media tanam terhadap pertumbuhan bibit tanaman nanas

\begin{tabular}{cccccccc}
\hline & \multicolumn{7}{c}{ Variabel pengamatan } \\
\cline { 2 - 8 } Perlakuan & $\begin{array}{c}\text { Panjang } \\
\text { akar }(\mathrm{cm})\end{array}$ & $\begin{array}{c}\text { Bobot kering } \\
\text { akar }(\mathrm{g})\end{array}$ & $\begin{array}{c}\text { Tinggi } \\
\text { tanaman }(\mathrm{cm})\end{array}$ & $\begin{array}{c}\text { Jumlah daun } \\
\text { (helai) }\end{array}$ & $\begin{array}{c}\text { Panjang } \\
\text { daun }(\mathrm{cm})\end{array}$ & $\begin{array}{c}\text { Lebar } \\
\text { daun }(\mathrm{cm})\end{array}$ & $\begin{array}{c}\text { Bobot } \\
\text { tajuk }(\mathrm{g})\end{array}$ \\
\hline $\mathrm{A}_{0} \mathrm{~B}_{1}$ & $19,88 \mathrm{a}$ & $0,15 \mathrm{a}$ & $7,01 \mathrm{a}$ & $7,34 \mathrm{a}$ & $26,87 \mathrm{a}$ & $2,77 \mathrm{a}$ & $28,98 \mathrm{a}$ \\
$\mathrm{A}_{0} \mathrm{~B}_{2}$ & $19,61 \mathrm{a}$ & $0,14 \mathrm{a}$ & $7,96 \mathrm{a}$ & $8,02 \mathrm{a}$ & $26,00 \mathrm{a}$ & $2,81 \mathrm{a}$ & $32,77 \mathrm{a}$ \\
$\mathrm{A}_{1} \mathrm{~B}_{1}$ & $18,62 \mathrm{a}$ & $0,20 \mathrm{a}$ & $8,20 \mathrm{a}$ & $7,92 \mathrm{a}$ & $27,56 \mathrm{a}$ & $2,86 \mathrm{a}$ & $43,96 \mathrm{a}$ \\
$\mathrm{A}_{1} \mathrm{~B}_{2}$ & $21,12 \mathrm{a}$ & $0,17 \mathrm{a}$ & $8,13 \mathrm{a}$ & $7,46 \mathrm{a}$ & $27,54 \mathrm{a}$ & $2,77 \mathrm{a}$ & $40,28 \mathrm{a}$ \\
$\mathrm{A}_{2} \mathrm{~B}_{1}$ & $21,09 \mathrm{a}$ & $0,22 \mathrm{a}$ & $7,36 \mathrm{a}$ & $7,99 \mathrm{a}$ & $27,19 \mathrm{a}$ & $2,88 \mathrm{a}$ & $41,39 \mathrm{a}$ \\
$\mathrm{A}_{2} \mathrm{~B}_{2}$ & $19,66 \mathrm{a}$ & $0,11 \mathrm{a}$ & $8,43 \mathrm{a}$ & $7,42 \mathrm{a}$ & $28,20 \mathrm{a}$ & $2,83 \mathrm{a}$ & $31,27 \mathrm{a}$ \\
$\mathrm{A}_{3} \mathrm{~B}_{1}$ & $20,00 \mathrm{a}$ & $0,15 \mathrm{a}$ & $6,38 \mathrm{a}$ & $8,23 \mathrm{a}$ & $25,95 \mathrm{a}$ & $2,75 \mathrm{a}$ & $46,34 \mathrm{a}$ \\
$\mathrm{A}_{3} \mathrm{~B}_{2}$ & $20,23 \mathrm{a}$ & $0,15 \mathrm{a}$ & $6,89 \mathrm{a}$ & $7,41 \mathrm{a}$ & $26,34 \mathrm{a}$ & $2,66 \mathrm{a}$ & $34,71 \mathrm{a}$ \\
$\mathrm{A}_{4} \mathrm{~B}_{1}$ & $20,37 \mathrm{a}$ & $0,12 \mathrm{a}$ & $6,38 \mathrm{a}$ & $8,29 \mathrm{a}$ & $24,87 \mathrm{a}$ & $2,60 \mathrm{a}$ & $21,08 \mathrm{a}$ \\
$\mathrm{A}_{4} \mathrm{~B}_{2}$ & $19,35 \mathrm{a}$ & $0,16 \mathrm{a}$ & $6,06 \mathrm{a}$ & $7,81 \mathrm{a}$ & $24,57 \mathrm{a}$ & $2,67 \mathrm{a}$ & $29,22 \mathrm{a}$ \\
\hline Rata-rata & 19,99 & 0,16 & 7,28 & 7,79 & 26,51 & 2,76 & 35,00 \\
\hline BNT & 4,17 & 0,09 & 2,19 & 1,32 & 3,13 & 0,25 & 20,17 \\
\hline
\end{tabular}

Keterangan: $A_{0}, A_{1}, A_{2}, A_{3}, A_{4}=$ rerturut-turut adalah konsentrasi IBA 0, 100, 200, 400, dan 600 ppm, $b_{1}$ dan $b_{2}=$ jenis media tanam pasir kali dan pasir vulkanik. Angka-angka sekolom diikuti dengan huruf yang sama menunjukkan tidak berbeda nyata berdasar uji BNT pada $\alpha=0,05$.

pucuk Anisoptera megistocarpa. Alrasyid dan Widiarti (1990) menemukan hal yang sama pada setek Khaya anthoteca yang diberi perlakuan IBA, ternyata tidak mempengaruhi perkembangan tunas atau jumlah daun yang ada pada setek tersebut.

Bibit tanaman nanas yang diberi IBA konsentrasi 600 ppm mampu menghasilkan jumlah akar primer bibit tanaman nanas terbanyak namun tidak berbeda dengan konsentrasi 200 dan 400 ppm dan berbeda dengan konsentrasi 0 dan 100 ppm (Tabel 1).
Sesuai dengan pernyataan McCown dan Wattimena (1988) bahwa pemberian IBA mampu meningkatkan kecepatan pengakaran sehingga kualitas dan vigor tanaman akan menigkat pula. Menurut Salisbury dan Ross (1995), IBA memegang peranan penting pada proses pembelahan dan pembesaran sel, terutama pada awal pembentukan akar.

Dijelaskan pula oleh Rochiman dan Harjadi (1973) dalam Lukitariati et al. (1996) bahwa jenis auksin IBA bersifat unggul dan efektif dalam merangsang aktivitas 
Tabel 3. Pengaruh perlakuan konsentrasi IBA (Indole Butyric Acid) dan jenis media tanam terhadap bobot basah akar bibit tanaman nanas

\begin{tabular}{ccc}
\hline \multirow{2}{*}{ Konsentrasi IBA } & \multicolumn{2}{c}{ Nllai tengah bobot basah akar $(\mathrm{g})$} \\
\cline { 2 - 3 } & \multicolumn{2}{c}{ Media tanam } \\
\cline { 2 - 3 } & Media tanam pasir kali & Media tanam pasir vulkanik \\
\hline \multirow{2}{*}{$0 \mathrm{ppm}$} & $0,56 \mathrm{abc}$ & $0,56 \mathrm{ab}$ \\
& $\mathrm{A}$ & $\mathrm{A}$ \\
$100 \mathrm{ppm}$ & $0,79 \mathrm{ab}$ & $0,59 \mathrm{ab}$ \\
& $\mathrm{A}$ & $\mathrm{A}$ \\
$200 \mathrm{ppm}$ & $0,86 \mathrm{a}$ & $0,41 \mathrm{~b}$ \\
& $\mathrm{~A}$ & $\mathrm{~B}$ \\
$400 \mathrm{ppm}$ & $0,54 \mathrm{bc}$ & $0,57 \mathrm{ab}$ \\
& $\mathrm{A}$ & $\mathrm{A}$ \\
$600 \mathrm{ppm}$ & $0,47 \mathrm{c}$ & $0,77 \mathrm{a}$ \\
& $\mathrm{A}$ & $\mathrm{A}$ \\
\hline
\end{tabular}

BNT
$\begin{gathered}\text { Keterangan: Angka-angka yang diikuti huruf } \\ \text { menunjukkantidak berbeda nyata berdasar uji BNT pada } \alpha=0,31\end{gathered}$

perakaran karena sifat kimianya yang stabil dan kemampuan kerjanya lebih lama. Menurut Wiesman et al. (1989) dalam Salisbury dan Ross (1995), IBA sangat aktif pada tempat yang diberikan, sekalipun cepat dimetabolismekan menjadi IBA-aspartat dan sekurangnya menjadi suatu konjugat dengan peptida lainnya. Salisbury dan Ross (1995) menjelaskan akibat terbentuknya konjugat tersebut diduga dapat menyimpan IBA, yang kemudian secara bertahap dilepaskan. Akibatnya konsentrasi IBA yang terikat akan digunakan pada tahap pembentukan akar selanjutnya.

Pengamatan yang dilakukan pada semua variabel tersebut di atas tidak menunjukkan adanya perbedaan, baik perlakuan konsentrasi IBA maupun jenis media tanam. Masing-masing nilai rata-rata variable tersebut adalah panjang akar 19,99 $\mathrm{cm}$, bobot basah akar 0,16 $\mathrm{cm}$, tinggi tanaman $7,28 \mathrm{~cm}$, jumlah daun 7.8 helai, panjang daun $26,51 \mathrm{~cm}$, lebar daun $2,76 \mathrm{~cm}$, dan bobot tajuk $35 \mathrm{~g}$ (Tabel 2).

Secara umum, perlakuan jenis media tanam yang digunakan yaitu campuran kompos : arang sekam : pasir kali $\left(b_{1}\right)$ dan campuran kompos : arang sekam : pasir vulkanik $\left(b_{2}\right)$ tidak memberikan pengaruh yang nyata pada semua variabel yang diamati. Hal ini diduga karena kedua media tanam yang digunakan ini memiliki sifat fisik yang relatif sama, seperti mampu mengikat dan menyimpan air dan hara dengan baik, memiliki aerasi dan drainase baik, tidak menjadi sumber penyakit, cukup porous sehingga mampu menyimpan oksigen yang diperlukan untuk proses respirasi. Kedunya mengandung arang sekam yang dapat menyerap racun pada ruang perakarn dan meningkatkan daya serap air (Marliana dan Rusnandi, 2007).

Sesuai dengan pernyataan Yasman dan Smits (1984) dalam Irwanto (2001) bahwa tekstur dan aerasi media yang baik lebih mempengaruhi pertumbuhan perakaran dibandingkan dengan sifat kimianya, seperti keasaman dan kandungan unsur hara. Oksigen yang cukup dalam media juga mampu mempercepat proses perakaran. Selain itu, pada kedua jenis media tanam digunakan kompos sebagai salah satu campuran media tanam yang digunakan. Kompos yang memiliki daya ikat terhadap tanah serta mampu menyimpan air tanah lebih lama ini menyebabkan pengaruh penggunaan media tanam pasir kali dan pasir vulkanik terhadap pertumbuhan bibit nanas tidak terlihat.

Hasil penelitian menunjukkan bahwa konsentrasi IBA terhadap bobot basah akar bergantung pada jenis media tanam (Tabel 3). Bobot basah akar yang dihasilkan oleh tanaman yang diberi IBA dengan konsentrasi 200 ppm dengan menggunakan media tanam pasir kali mampu menghasilkan bobot basah akar tertinggi bila dibandingkan dengan konsentrasi lainnya, sedangkan pada penggunaan media tanam pasir vulkanik, bobot basah akar tertinggi dihasilkan oleh tanaman yang diberikan IBA dengan konsentrasi 600 ppm. Sebaliknya, pengaruh konsentrasi IBA yang diberikan ditentukan oleh jenis media tanam yang digunakan.

Pertumbuhan akar disebabkan oleh IBA yang menginisiasi pemanjangan sel dengan cara 
mempengaruhi pelenturan dinding sel. Dijelaskan oleh Salisbury dan Ross (1995), bahwa IBA mengakibatkan sel penerima mengeluarkan $\mathrm{H}^{+}$ke dinding sel primer yang mengelilinginya dan kemudian menurunkan $\mathrm{pH}$ sehingga terjadi peningkatan elastisitas dinding dan pertumbuhan yang cepat. Kondisi $\mathrm{pH}$ yang rendah ini diduga mengaktifkan enzim yang dapat memutuskan ikatan pada polisakarida dinding sel, sehingga memungkinkan dinding lebih mudah merengang.

Selain memacu pemanjangan sel yang menyebabkan pertumbuhan akar, akibat pemberian zpt pada dasarnya dapat meningkatkan pemanfaatan hara diantaranya $\mathrm{N}, \mathrm{Mg}, \mathrm{Fe}$ dan $\mathrm{Cu}$ untuk membentuk klorofil yang sangat diperlukan untuk meningkatkan fotosintesis. Dengan fotosintesis yang semakin meningkat akan dihasilkan hasil fotosintesis yang meningkat pula dan bersamaan dengan auksin akan bergerak ke akar untuk memacu pembentukan giberelin dan sitokinin di akar yang akan membantu pembentukan dan perkembangan akar (Wareing, 1976) dalam Lukitariati et al. (1996).

Hal tersebut senada dengan yang diungkapkan George (1996) bahwa pemberian larutan atau bubuk yang mengandung auksin akan meningkatakan jumlah akar yang terbentuk dan meningkatkan keberhasilan penyetekan. Pertumbuhan akar yang baik diindikasikan oleh penambahan jumlah akar yang secara langsung akan meningkatkan bobot akar. Hal ini disebabkan IBA yang diberikan pada konsentrasi yang tepat mampu memperbaiki tingkat pertumbuhan akar yang mengakibatkan proses penyerapan air dan unsure hara menjadi lebih baik sehingga mempengaruhi bobot basah akar nanas. Namun besarnya bobot basah tanaman tidak sejalan dengan bobot kering akar nanas yang dihasilkan.

\section{KESIMPULAN}

Berdasarkan hasil penelitian dapat disimpulkan bahwa pemberian IBA konsentrasi 600 ppm dapat meningkatkan jumlah akar bibit tanaman nanas. Perbedaan media tanam yang digunakan tidak berpengaruh pada semua variabel yang diamati. Pemberian IBA konsentrasi 200 ppm dapat meningkatkan bobot basah akar bibit tanaman nanas apabila ditanam pada media campuran pasir kali : arang sekam : kompos.

\section{DAFTAR PUSTAKA}

Alrasyid, H. \& A. Widiarti. 1990. Pengaruh Penggunaan Hormon IBA terhadap Persentase Hidup Stek
Khaya anthoteca. Buletin Penelitian Hutan No.523. Pusat Penelitian dan Pengembangan Kehutanan. Bogor.

Adesidjo. 2008. Media Tanam. Dalam http:// www.adesidjo.com/mediatanam.htm. Diakses 10 Februari 2012.

Ardisela, D. 2010. Pengaruh Dosis Rootone-F terhadap Pertumbuhan Crown Tanaman Nenas (Ananas comosus). J. Agribisnis dan Pengembangan Wilayah. 1(2): 48-62.

Badan Pusat Statistika. 2011. Statistics Indonesia. BPS Jakarta- Indonesia. Halaman 73. http:// www.bps.go.id. Diakses 10 Maret 2012.

George, E.F. 1996. Plant Propagation by Tissue Culture. Second Edition 1993/1996. Exegetics Limited. England.

Hartmann, H.T., D.E. Kester, \& F.T. Davies Jr. 1997. Plant Propagation Principles And Practices. Fifth edition. Pentice-Hall, Inc. Engle Wood. New Yersey.

Irwanto. 2001. Pengaruh Hormon IBA (Indole Butyric Acid) terhadap Persen Jadi Stek Pucuk Meranti Putih (Shorea montigena). Skripsi. Universitas Pattimura. Ambon.

Kapisa, N. \& E. Sapulete. 1994. Percobaan stek pucuk Anisoptera megistrocarpa. Buletin Penelitian Kehutanan Vol X (3). Parapat, Balai Penelitian Kehutanan Pematang Siantar.

Lukitariati S., N.L.P. Indriyani, A. Susiloadi, \& M.J. Anwarudin. 1996. Pengaruh naungan dan konsentrasi Asam Indol Butirat terhadap pertumbuhan bibit batang bawah manggis. Jurnal Hortikultura 6 (3): 220-226.

Marliana, M. \& D. Rusnandi. 2007. Teknik aklimatisasi Anthurium pada beberapa media tanam. Bulletin Teknik Pertanian. 12 (1): 38 40.

Rachmawati, Y.A. 2008. Pengaruh Konsentrasi IBA dan Jumlah Buku pada Keberhasilan Penyetekan Sirih Merah (Piper crocatum Ruiz and Pav.) dengan Media Pasir Malang. Skripsi. Universitas Lampung. Bandar Lampung.

Rosmaina. 2011. Pengaruh perlakuan BA dan NAA terhadap pembentukan akar nenas (Ananas comosus (L). Merr.) cv. Smooth Cayenne secara in Vitro. J. Agroteknologi. 1(2):37-44. 
Salisbury, F.B. \& C.W. Ross. 1995. Plant Physiology. Third Edition. WadsworthPubl. Co. Belmont, California.

Samson, J.A. 1986. Tropical Fruits. Longman, John Willey \& Sons. Inc. New York.
Wattimena, G.A. 1988. Zat Pengatur Tumbuh Tanaman. Laboratorium Kultur Jaringan Tanaman PAU Bioteknologi IPB. Bogor. 